\title{
Case Report: Migrainous Infarct without Aura
}

\author{
Kamesh Gupta ${ }^{a} \quad$ Anurag Rohatgi ${ }^{a}$ Shivani Handa ${ }^{b}$ \\ ${ }^{a}$ Department of Medicine, Ram Manohar Lohia Hospital, New Delhi, India; ${ }^{b}$ Department of \\ Medicine, Saral Diagnostics, Delhi, India
}

\section{Keywords}

Case report · Migraine without aura $\cdot$ Migrainous infarct $\cdot$ Stroke in migraine without aura

\begin{abstract}
Background: Stroke in a migraine with aura has been documented in several cases, even deserving the merit of a classification as complicated migraine. Herein, we present a rare case of migrainous infarct without aura. The diagnosis was challenging due to lack of risk factors. The patient was unique in not having any other comorbidities. Case Presentation: The case is of a 21-year-old female presenting with right-sided hemiplegia and facial drooping. She had had an index presentation of throbbing headaches for the past 2 years, typical of a migraine but not preceded by any aura symptoms. However, in the current episode, the pain became excessively severe and accompanied by right-sided hemiplegia and facial drooping. A full investigation workup using MRI revealed evidence of infarct in the left temporoparietal and basal ganglion region. Conclusion: Our case highlights the need to evaluate silent ischemic stroke in case of prolonged headache with a history of migraine as well as the need for precaution to avoid the use of triptans or opioids in such a case. It also highlights the conditions that need to be excluded before labeling it as a migrainous infarct.
\end{abstract}




\section{Case Reports in Neurology}

\section{Introduction}

Migraine is the most common type of headache in young adults. Some observational studies have shown an increase in the risk of stroke among people with a history of migraine [1], but others have failed to find this association [2]. The proponents mention the pathophysiology of platelet hyperaggregability and the reduction in cerebral blood flow that usually occurs in migraine with aura [3]. However, in a few studies [4, 5], strokes have also been observed in patients with migraine without aura. Herein, we report a rare case of migraine without aura presenting with stroke along with the relevant investigations.

\section{Case Presentation}

Patient Demographics, Chief Complaint and Past History

A 21-year-old, right-handed Indian female presented to the Emergency Department of Smt. Sucheta Kriplani Hospital, New Delhi, India.

She had had an index presentation of periodic left hemicranial headache about once a month for the past 2 years. The patient was accompanied by her mother. The history was given by the patient herself. Her headache was severe in intensity $(7 / 10$ according to the Numeric Pain Rating Scale [6]), throbbing in character, usually lasting 1-2 $\mathrm{h}$ and often associated with nausea and vomiting. It was aggravated by loud noises and flashing lights. The symptoms were relieved by taking self-prescribed NSAIDs. The patient was conscious during these episodes and did not give any history suggestive of aura preceding any of these episodes of headache. She did not seek any medical help. One day before admission, the patient's headache became excessively severe (9/10 according to the Numeric Pain Rating Scale [6]), continuous and unresponsive to analgesics. Two hours into the episode, she noticed sudden-onset clumsiness of her right hand soon followed by dragging of her right foot while walking. Within the next hour, she developed right facial drooping and slurring of speech, after which her mother called the emergency services. The patient was admitted for medical services.

This episode was not preceded by fever, arthritis, head trauma, syncope, or seizure. She did not have hypertension, diabetes mellitus, heart disease, or any respiratory ailment and was not a consumer of tobacco or alcohol, or any known stimulants. She was not on any medication including oral contraceptive pills. There was no family history of migraine, stroke, or seizures.

\section{Physical Examination}

On examination, the patient was afebrile and without pallor, icterus, cyanosis, rash, or abnormal skin pigmentation. On further examination, no lymph nodes were palpable, bilateral carotid pulses were palpable, no cervical bruit was heard, and the cardiopulmonary, abdominal, and musculoskeletal examinations were noncontributory. The neurological examination revealed upper motor neuron type right facial nerve palsy with slurred speech but preserved comprehension. Motor examination showed mild hemiparesis of upper motor neuron type. The patient was admitted and investigated. 


\section{Case Reports in Neurology}

\section{Diagnostic Assessment}

The detailed laboratory investigations revealed a normal hemogram, blood sugar, lipid profile, kidney function and liver function tests, and electrolytes profile, as shown in Table 1. She was nonreactive to HIV, and a detailed workup for thrombophilia (Table 2) was negative. Her blood profile for autoimmune markers (Table 3) was nonreactive. The chest X-ray, ECG, 2D echo, and transesophageal echocardiography (Fig. 1) (specifically for the presence of patent foramen ovale), done subsequently, were unremarkable. A diagnostic lumbar puncture performed to rule out subarachnoid hemorrhage and cerebral angiitis did not reveal any abnormalities (Table 4). A detailed neuroimaging evaluation was done consisting of conventional and post-gadolinium sequences on a 1.5-T MR scanner (Fig. 2, 3) and postcontrast angiography with volume reconstruction (arch vessels, neck, and cerebral vessels) on multidetector CT (Fig. 4) was obtained. The American Academy of Neurology updated their guidelines in July 2010, recommending diffusion-weighted imaging as the superior method (level A) for the most accurate stroke diagnosis [7]. Diffusion-weighted imaging at a $\mathrm{b}$ value of 0 and 1,000 ms demonstrated restricted diffusion in the left capsuloganglionic region with low signal on the corresponding apparent diffusion coefficient map, suggestive of an acute infarct. The radiological findings correlated with the clinical findings of rightsided hemiplegia. The other imaging did not reveal evidence of thrombosis of the circle of Willis, dural venous sinus thrombosis, arteriovenous malformations, carotid dissection, or any visible white or gray matter abnormalities.

\section{Interventions and Follow-Up}

The patient could not undergo thrombolysis as she presented outside the window period but her headache resolved with intravenous analgesics. There was rapid recovery to 5/5 motor power within $24 \mathrm{~h}$ of admission; however, the facial palsy persisted. She was discharged on $75 \mathrm{mg}$ of aspirin daily along with weekly outpatient follow-ups. She was advised to keep a log of her medical history and to keep her medical advisory band on at all times.

\section{Discussion}

Migraine with aura has been consistently associated with increased risk of ischemic stroke. Most studies suggest that this association is particularly strong for young women. Also, migraine, predominantly one with aura, is associated with the presence of silent infarctions or white matter changes [8]. Whether the relationship between migraine and stroke is the consequence of other underlying etiologies or the presence of ischemic risk factors, or whether migraine is associated with conditions that could potentially cause stroke is yet to be determined $[9,10]$. The mechanism of this potential association is believed to be in part through platelet hyperaggregability and the reduction in cerebral blood flow that usually occurs in migraine with aura [3]. Stroke during a migraine attack is known as complicated migraine. According to the International Headache Society classification, complicated migraine occurs only in attacks of migraine with aura. However, studies have shown cases of stroke also during attacks of migraine without aura. A survey carried out by Milhaud et al. [4] in 3,502 patients with ischemic stroke found strokes to be more common during attacks of migraine without aura, thus, calling for revision of the International Headache Society 


\section{Case Reports in Neurology}

classification. In young migraineurs, the posterior circulation involvement and the presence of patent foramen ovale were characteristic [4]. He proposed that excessive sympathetic nervous system activation occurs due to prolonged severe pain and results in arterial vasoconstriction and activation of the coagulation cascade. The posterior cerebral circulation is more prone to sympathetic nervous system stimulation. Hence, our case findings are consistent with studies by Milhaud et al. [4].

This case has similarities with reversible cerebral vasoconstriction syndrome (RCVS) due to the sudden onset of thunderclap headache and the stroke findings. However, since there is no evidence of string beading constriction on CT angiography, RCVS is unlikely [11]. Also, in RCVS patients, stroke appears usually 1-3 weeks after the onset of a first headache, which was the type of history in our patient $[12,13]$. In recent prospective studies of recurrent RCVS, the middle cerebral artery was involved in all cases $[14,15]$.

Primary angiitis of the central nervous system (PACNS) is a rare disorder affecting both medium- and small-sized vessels. In PACNS, serum findings are usually normal, but CSF studies reveal inflammatory findings. These include mild lymphomonocytic pleocytosis or protein elevation in more than $90 \%$ of patients [16]. Since in our patient no CSF abnormalities were found, the gold standard of PACNS diagnosis, which is biopsy of leptomeninges and cerebral meninges, was not performed.

The diagnosis of Sneddon syndrome is based on the presence of fixed deep bluish-red reticular skin lesions on the legs and body (livedo racemosa) associated with strokes [16]. MRI performed with and without contrast medium is the investigation of choice to detect and monitor cerebral involvement [17]. It shows vessel wall edema and thickening.

The other important aspect about patients with migrainous infarcts is the treatment of such patients. Triptans, considered to be the drug of choice for acute attacks of migraine, are contraindicated in such patients due to the mechanism of action of causing vasoconstriction. It has been proposed that patients should carry a card with them informing physicians about their disorder so that they are not administered triptans during acute attacks in future.

\section{Conclusion}

Although migraine without aura has a lower risk of ischemic infarct, the identification of patients who are at higher risk for developing cerebral infarction is essential in managing the patient. The use of oral contraceptives, triptans, and ergotamines should be employed with caution in these patients. Before labeling it as "migrainous stroke," other hypercoagulable states and autoimmune conditions must be excluded. However, our case was unique as none of the associated risk factors were found in our patient.

\section{Statement of Ethics}

Approval was received from the Ethics Board of the University of Delhi. Written informed consent was obtained from the patient for publication of this case report and any 
accompanying images. A copy of the written consent is available for review by the Editor-inChief of this journal.

\section{Disclosure Statement}

The authors declare that there is no conflict of interest regarding the publication of this manuscript.

\section{Author Contribution}

K.G. made significant contributions to the acquisition of data and their analysis and interpretation. A.R. contributed to the concept and design. S.H. contributed in the writing of the article. All authors read and approved the final manuscript.

\section{References}

1 Tzourio C, Tehindrazanarivelo A, Iglesias S, Alperovitch A, Chedru F, d'Anglejan-Chatillon J, et al: Casecontrol study of migraine and risk of ischaemic stroke in young women. BMJ 1995;310:830-833.

2 Carolei A, Marini C, De Matteis G: History of migraine and risk of cerebral ischaemia in young adults. Lancet 1996;347:1503-1506.

-3 Woods RP, Iacoboni M, Mazziotta JC: Brief report: bilateral spreading cerebral hypoperfusion during spontaneous migraine headache. N Engl J Med 1994;331:1689-1692.

4 Milhaud D, Bogousslavsky J, van Melle G, Liot P: ischemic stroke and active migraine. Neurology 2001;57:1805-1811

5 Etminan M, Takkouche B, Isorna FC, Samii A: Risk of ischaemic stroke in people with migraine: systematic review and meta-analysis of observational studies. BMJ 2005;330:63.

6 McCaffery M, Pasero C: 0-10 numeric pain rating scale; in McCaffery M, Pasero C (eds): Pain: Clinical Manual. St Louis, Mosby, 1999, p 16.

7 Schellinger PD, Bryan RN, Caplan LR, et al: Evidence-based guideline: the role of diffusion and perfusion MRI for the diagnosis of acute ischemic stroke - report of the Therapeutics and Technology Assessment Subcommittee of the American Academy of Neurology. Neurology 2010;75:177-185.

8 Gladstone JP, Dodick DW: Migraine and cerebral white matter lesions: when to suspect CADASIL. Neurologist 2005;11:19-29. Agostoni E, Aliprandi A: The complications of migraine with aura. Neurol Sci 2006;27(suppl 2):S91S95.

$>10$ Glenn AM, Shaw PJ, Home JW, Bates D: Complicated migraine resulting in blindness due to bilateral retinal infarction. Br J Ophthalmol 1992;76:189-190.

11 Sattar A, Manousakis G, Jensen MB: Systematic review of reversible cerebral vasoconstriction syndrome. Expert Rev Cardiovasc Ther 2010;8:1417-1421.

12 Ducros A, Boukobza M, Porcher R, Sarov M, Valade D, Bousser MG: The clinical and radiological spectrum of reversible cerebral vasoconstriction syndrome: a prospective series of 67 patients. Brain 2007;130:3091-3101.

13 Singhal AB, Caviness VS, Begleiter AF, Mark EJ, Rordorf G, Koroshetz WJ: Cerebral vasoconstriction and stroke after use of serotonergic drugs. Neurology 2002;58:130-133.

14 Chen SP, Fuh JL, Lirng JF, et al: Recurrent primary thunderclap headache and benign CNS angiopathy: spectra of the same disorder? Neurology 2006;67:2164-2169.

15 Chen SP, Fuh JL, Chang FC, et al: Transcranial color Doppler study for reversible cerebral vasoconstriction syndromes. Ann Neurol 2008;63:751-757. 


\section{Case Reports in Neurology}

16 Berlit P: Diagnosis and treatment of cerebral vasculitis. Ther Adv Neurol Disord 2010;3:29-42.

17 Pipitone N, Salvarani C: Role of imaging in vasculitis and connective tissue diseases. Best Pract Res Clin Rheumatol 2008;22:1075-1091.

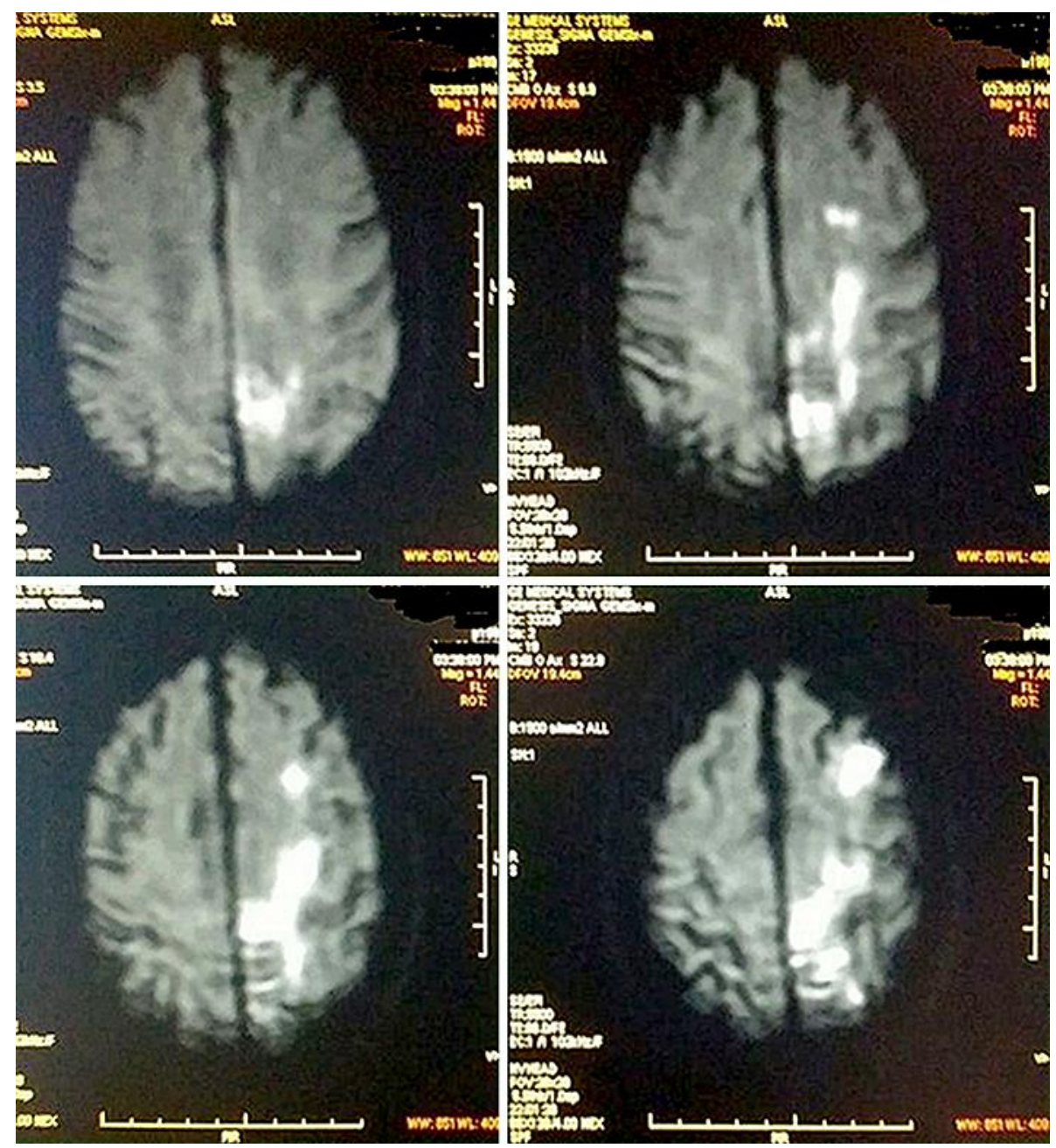

Fig. 1. Transesophageal echocardiography - normal study; excluding the possibility of a patent foramen ovale. 


\section{Case Reports in Neurology}
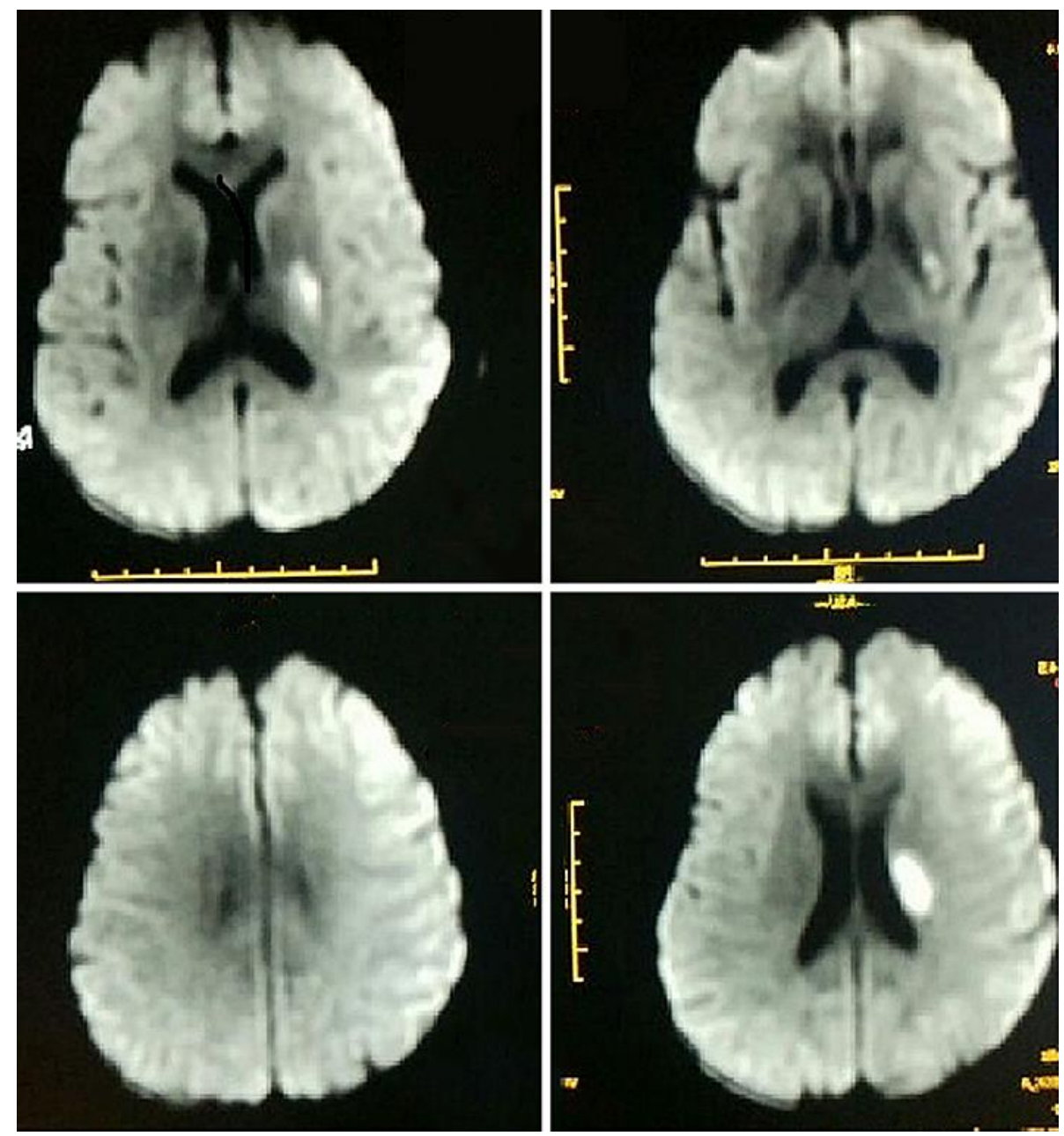

Fig. 2. MRI showing infarct in the left temporoparietal and basal ganglion region. 


\section{Case Reports in Neurology}

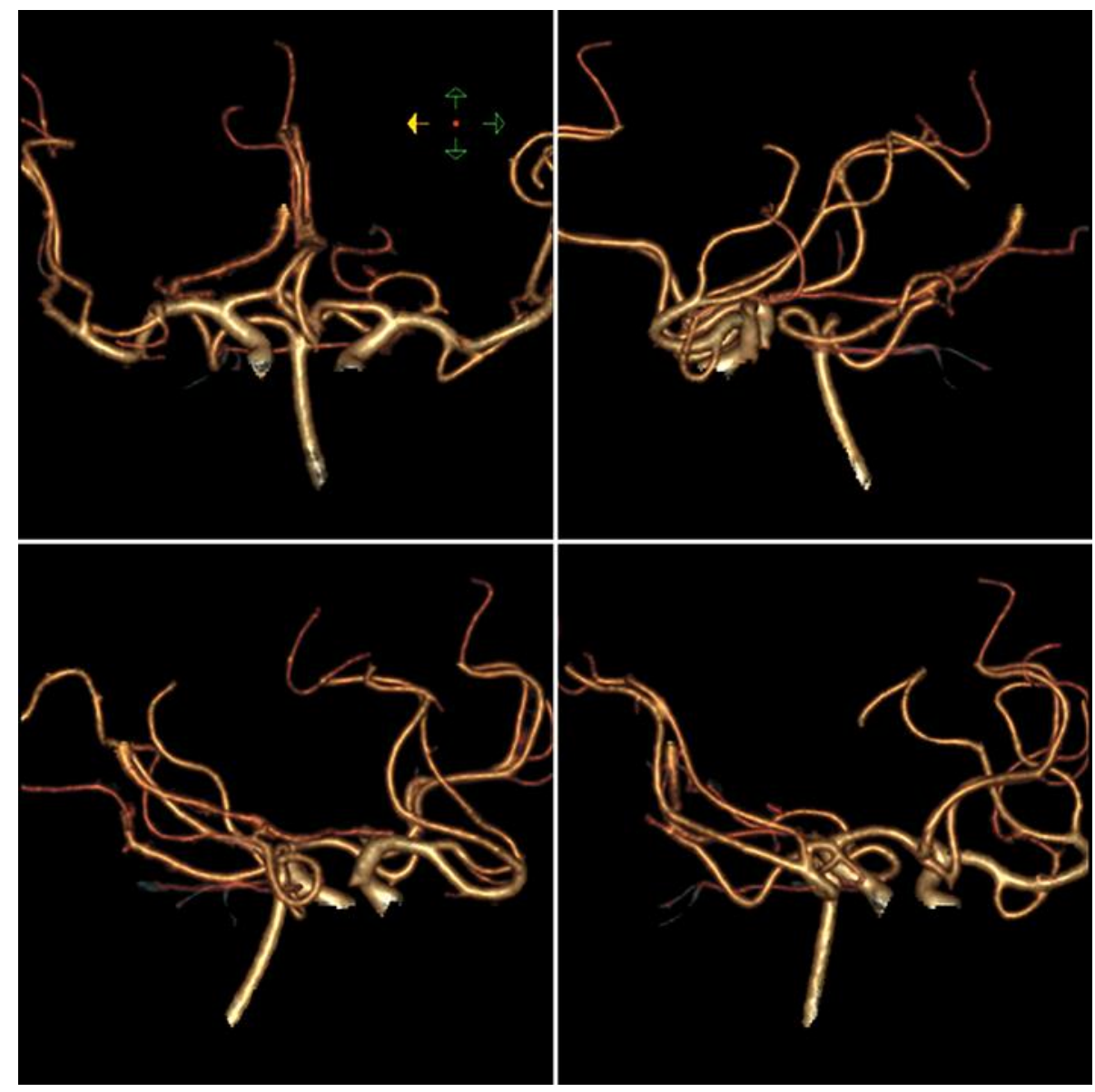

Fig. 3. MRI showing infarct in the left temporoparietal and basal ganglion region. 


\section{Case Reports in Neurology}

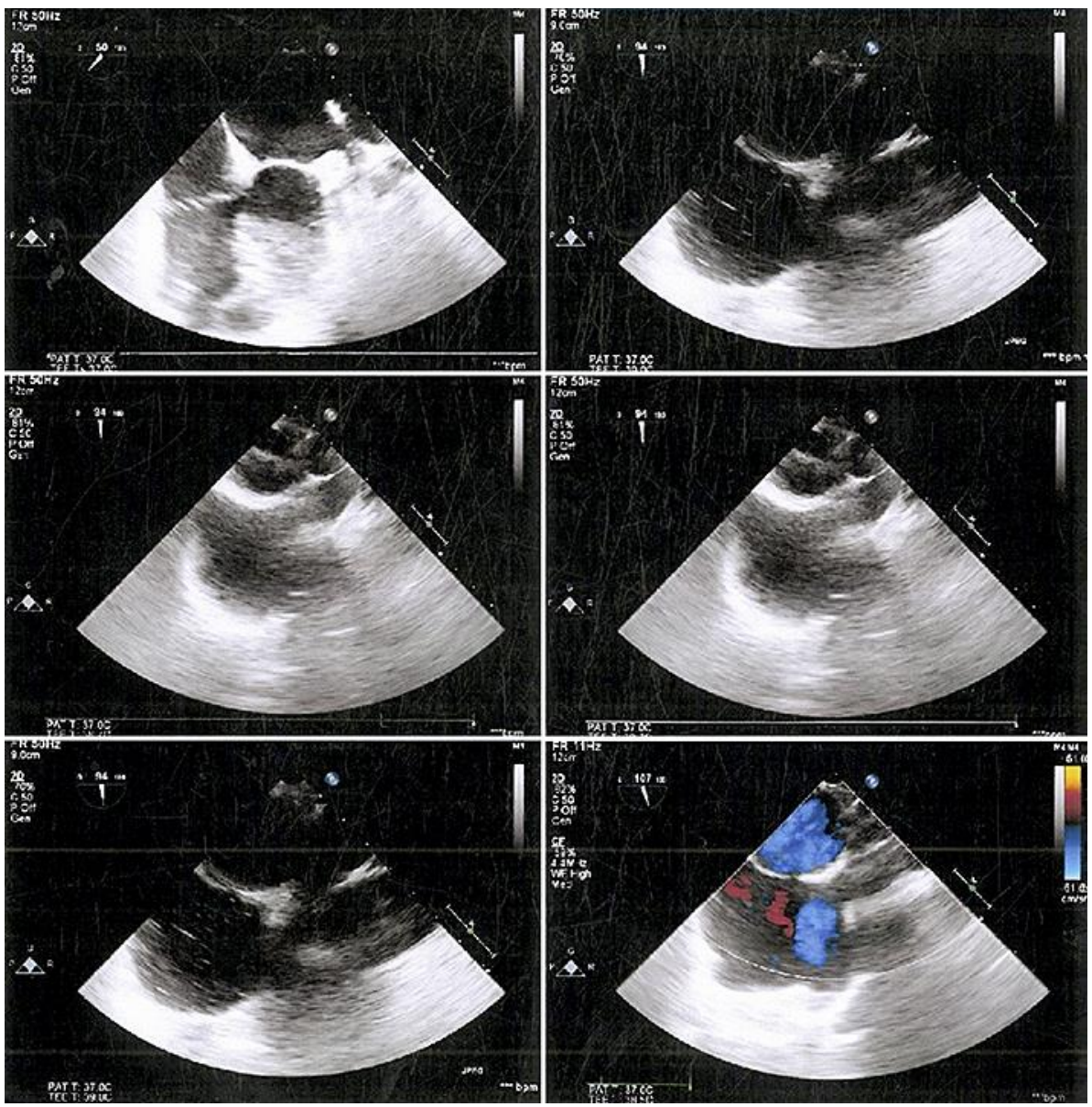

Fig. 4. CT angiography of the circle of Willis and its branches - there is no evidence of any vasoconstriction. 
Table 1. Basic blood panel

\begin{tabular}{ll}
\hline Hemoglobin & $13.2 \mathrm{~g} / 100 \mathrm{~mL}$ \\
RBC count & $4.8 \times 10^{3} / \mathrm{m}^{3}$ \\
PCV & $41 \%$ \\
TLC & $7,300 / \mathrm{m}^{3}$ \\
Platelet count & $3,10,000 / \mathrm{mL}$ \\
Peripheral smear & Normal \\
ESR & $7 \mathrm{~mm}$ at the end of $1 \mathrm{~h}$ \\
\hline Fasting blood sugar & $79 \mathrm{mg} / \mathrm{dL}$ \\
PP blood sugar & $103 \mathrm{mg} / \mathrm{dL}$ \\
HbA1C & $4.1 \%$ \\
\hline Blood urea nitrogen & $14 \mathrm{mg} / \mathrm{dL}$ \\
Creatinine & $1.1 \mathrm{mg} / \mathrm{dL}$ \\
Routine urine for albumin & $\mathrm{Nil}$ \\
\hline Serum cholesterol & $115 \mathrm{mg} / \mathrm{dL}$ \\
Serum HDL & $53 \mathrm{mg} / \mathrm{dL}$ \\
Serum LDL & $76 \mathrm{mg} / \mathrm{dL}$ \\
Serum triglycerides & $64 \mathrm{mg} / \mathrm{dL}$ \\
Serum VLDL & $17 \mathrm{mg} / \mathrm{dL}$ \\
Total cholesterol/HDL & 2.3 \\
\hline Serum bilirubin & $0.8 \mathrm{mg} / \mathrm{dL}$ \\
SGOT & $14 \mathrm{units} / \mathrm{mL}$ \\
SGPT & $18 \mathrm{units} / \mathrm{mL}$ \\
Alkaline phosphatase & $87 \mathrm{units} / \mathrm{mL}$ \\
Gamma GT & $13 \mathrm{units} / \mathrm{mL}$ \\
Serum albumin & $4.7 \mathrm{~g} \%$ \\
\hline Serum sodium & $137 \mathrm{mEq} / \mathrm{L}$ \\
Serum potassium & $3.9 \mathrm{mEq} / \mathrm{L}$ \\
Serum chloride & $96 \mathrm{mEq} / \mathrm{L}$ \\
Serum calcium & $9.2 \mathrm{mg} / \mathrm{dL}$ \\
Serum phosphorus & $2.7 \mathrm{mg} / \mathrm{dL}$ \\
Serum bicarbonate & $24 \mathrm{mEq} / \mathrm{L}$ \\
Serum acid phosphatases & $1.5 \mathrm{KA} \mathrm{units}$ \\
\hline
\end{tabular}


Table 2. Coagulation workup

\begin{tabular}{ll}
\hline PT & $12 \mathrm{~s}$ \\
PTT & $35 \mathrm{~s}$ \\
INR & 1.2 \\
Protein C & $117 \mathrm{IU} / \mathrm{dL}(n=65-135 \mathrm{IU})$ \\
Protein S & $104 \mathrm{IU} / \mathrm{dL}(n>63 \mathrm{IU} / \mathrm{dL})$ \\
Activated protein C resistance ratio & $2.9(n>2.1)$ \\
Antithrombin III reference range & $92 \%$
\end{tabular}

Table 3. Autoimmune workup

ANA

RF

ASO titer

Anti cardiolipin antibodies
1:20 dilution $(n<1: 40)$

$4 \mathrm{IU} / \mathrm{mL}(n<15 \mathrm{IU} / \mathrm{mL})$

$60 \mathrm{IU} / \mathrm{mL}(n<200 \mathrm{IU})$

Negative

Table 4. Diagnostic lumbar puncture

\begin{tabular}{ll}
\hline Color & Clear \\
$\mathrm{pH}$ & 7.31 \\
Glucose & $70 \mathrm{mg} / \mathrm{dL}$ \\
LDH & $1.9 \mathrm{U} / \mathrm{mL}$ \\
Proteins & $24 \mathrm{mg} / \mathrm{dL}$ \\
Erythrocyte count & $3 / \mathrm{mm}^{3}$ \\
Leukocyte count & $2 / \mathrm{mm}^{3}$ \\
Antibodies, viral DNA & None \\
Bacteria (gram staining, culture) & None \\
Protein electrophoresis & Normal \\
\hline
\end{tabular}

